\title{
Secondary Hyperparathyroidism: Pathophysiology and Treatment
}

Wissam Saliba, MD, and Boutros El-Haddad, MD

Secondary hyperparathyroidism is a frequently encountered problem in the management of patients with chronic kidney disease (CKD). Its pathophysiology is mainly due to hyperphosphatemia and vitamin D deficiency and resistance. This condition has a high impact on the mortality and morbidity of dialysis patients. Early diagnosis of secondary hyperparathyroidism is crucial in the management of patients with CKD. The treatment remains a challenge for patients and their clinicians. It should include a combination of dietary phosphorus restriction, phosphate binders, vitamin $\mathbf{D}$ analogues, and calcimimetics. (J Am Board Fam Med 2009;22:574-581.)

\section{Background}

The prevalence of chronic kidney disease (CKD) in the United States has increased from 10\% during 1988 to 1994 to around $13 \%$ during 1999 to 2004 . This goes in pair with an increasing prevalence of diabetes mellitus and hypertension. Current classification of CKD is based on the presence of parenchymal damage for stages I and II and a decrease in glomerular filtration rate (GFR) regardless of parenchymal damage for stages III and higher ${ }^{1}$ (Table 1). CKD stage III is the most common CKD stage, with a rate reaching $30 \%$ in patients older than 70 years of age. ${ }^{2}$ This high number of CKD patients represents a challenge for both nephrologists and primary care physicians, especially when dealing with blood pressure, anemia, volume status, and, most importantly, the combination of secondary hyperparathyroidism and mineral bone disease. This article reviews the mechanisms and causes of secondary hyperparathyroidism and provides a stepped approach for its management.

\section{Calcium and Phosphorus Homeostasis}

The homeostasis of calcium and phosphorus is the result of complex relations between calcemia, phos-

This article was externally peer reviewed.

Submitted 7 February 2009; revised 14 April 2009; accepted 21 April 2009.

From Department of Internal Medicine, University of Kansas School of Medicine, Wichita.

Funding: none.

Conflict of interest: none declared.

Corresponding author: Wissam Saliba, MD, Department of Internal Medicine, University of Kansas School of Medicine, 505 North Rock Road, Apt \#1436, Wichita, KS 67206 (E-mail: salibawissam@hotmail.com). phatemia, and different hormones and factors working synergistically to keep a normal balance of these minerals (Fig. 1).

\section{Parathyroid Hormone}

The parathyroid hormone (PTH) is the most important regulator of calcium metabolism. It is a polypeptide consisting of 84 amino acids and is secreted by the chief cells of the parathyroid glands in response to hypocalcemia and hyperphosphatemia. It has a short half-life (2 to 4 minutes) before being degraded to various inactive fragments. Although "intact" PTH assay is widely used to estimate active PTH level, it may react with some of its fragments. New assays, called "whole" PTH, have been recently developed for better measurement of full-length PTH. ${ }^{3}$ PTH acts mainly on 2 organs: the bone and the kidney.

1. It stimulates the osteoclasts and causes bone resorption, resulting in an increase in the serum concentration of calcium and phosphorus.

2. PTH stimulates the 1- $\alpha$ hydroxylase activity in the kidney, resulting in an increase in 1,25 dihydroxyvitamin D production. It also increases the reabsorption of calcium in the distal renal tubules, decreasing calcium clearance. The effect on phosphorus clearance is the opposite. PTH can decrease the reabsorption of phosphorus in the proximal renal tubules from $85 \%$ in healthy individuals to less than $15 \%$ in dialysis patients. $^{4}$

3. Of note, PTH has no direct established activity on the intestine. However, it indirectly increases intestinal calcium and phosphorus absorption 
Table 1. Stages of Chronic Kidney Disease

\begin{tabular}{llc}
\hline Stage & \multicolumn{1}{c}{ Description } & $\begin{array}{c}\text { GFR } \\
\left(\mathrm{mL} / \mathrm{min} / 1.73 \mathrm{~m}^{2}\right)\end{array}$ \\
\hline I & $\begin{array}{c}\text { Kidney damage with normal/ } \\
\text { increased GFR }\end{array}$ & $\geq 90$ \\
& $\begin{array}{c}\text { Kidney damage with mild } \\
\text { II }\end{array}$ & $60-89$ \\
III & Mocrease in GFR & $30-59$ \\
IV & Severe decrease in GFR & $15-29$ \\
V & Kidney failure & $<15$ \\
\hline
\end{tabular}

Adapted from the National Kidney Foundation, used with permission.

GFR, glomerular filtration rate.

via stimulation of 1,25 dihydroxyvitamin $\mathrm{D}$ production. The results of high PTH are hypercalcemia, hypophosphatemia, and high urinary calcium and phosphorus.

4. Calcium has a negative feedback effect on the parathyroid glands through the calcium sensing receptor. ${ }^{5}$ Recently, phosphorus has been shown to have a direct stimulatory effect on the parathyroid glands. ${ }^{6}$

\section{Vitamin $D$}

Vitamin D is an essential factor in the regulation of calcium and phosphorus balance. It is synthesized in the skin but is also present in the diet. The active form is 1,25 dihydroxyvitamin D. Its main action is to enhance the availability of calcium and phosphorus for new bone formation. Recent studies have also shown important actions of vitamin D in many other tissues. Vitamin D enhances the intestinal absorption of calcium and phosphorus, increasing their serum levels.

1. Along with PTH, vitamin D is a required factor in the bone resorption process.

2. It also increases the reabsorption of urinary calcium and phosphorus in the renal tubules.

3. Through the vitamin $\mathrm{D}$ receptors it has a direct effect on the parathyroid glands to suppress PTH secretion. ${ }^{7}$

\section{Fibroblasts Growth Factor-23}

Until recently, it was thought that the phosphorus homeostasis was mainly achieved by PTH and vitamin D. Recent studies identified fibroblasts growth factor (FGF)-23 as a new protein with phosphaturic activity. It is mainly secreted by os-

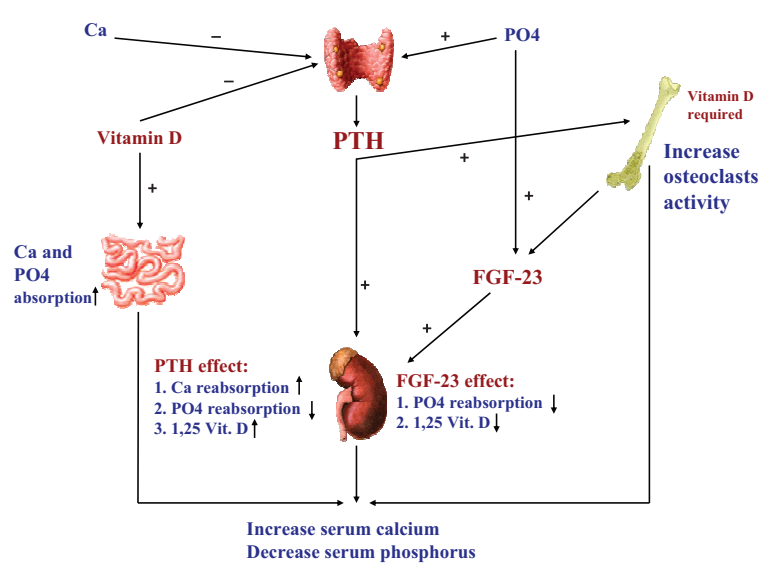

Figure 1. Normal calcium and phosphorus homeostasis. PTH, parathyroid hormone; FGF-23, fibroblasts growth factor 23 .

teocytes and is now considered to be the most important factor for regulation of phosphorus homeostasis.

1. Through the Klotho receptor it acts mainly on the kidney to increase phosphorus clearance. ${ }^{8}$

2. FGF-23 also inhibits the $1-\alpha$ hydoxylase activity, causing a low 1,25 dihydroxyvitamin D level.

3. Hyperphosphatemia is the principal stimulator for FGF-23.

4. It is not yet proven if there is any direct relation between PTH and FGF-23.

\section{Calcium and Phosphorus Metabolism in Renal Failure}

When GFR falls, the phosphorus clearance decreases significantly, leading to phosphorus retention. This hyperphosphatemia, subclinical when estimated GFR is $>30 \mathrm{~mL} / \mathrm{min}$, is thought to be the principal cause of secondary hyperparathyroidism (Fig. 2). Phosphorus induces PTH secretion by 3 mechanisms:

1. Direct stimulatory effect on the parathyroid glands as previously mentioned.

2. Induction of mild hypocalcemia by precipitating with calcium as $\mathrm{CaHPO}_{4}$. Hypocalcemia also results from decreased calcium release from bone pools.

3. Stimulation of FGF-23, which leads to severe inhibition of 1- $\alpha$ hydroxylase and depressed level of 1,25 dihydroxyvitamin D. ${ }^{9}$ The downregulation of the vitamin $\mathrm{D}$ receptors on the 


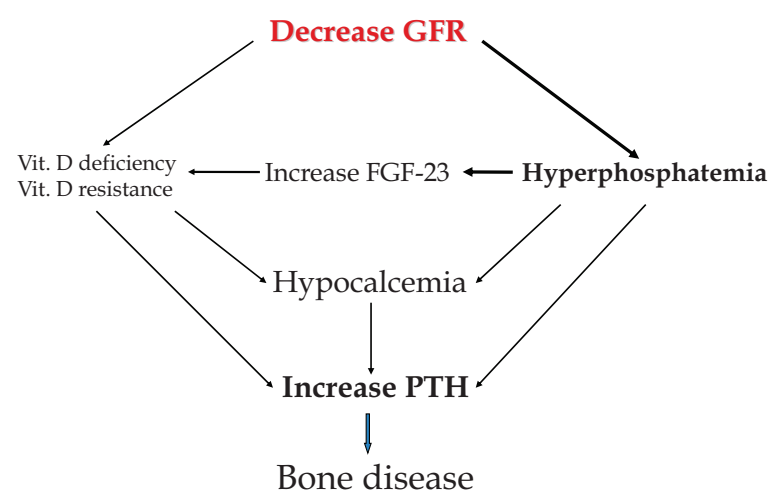

Figure 2. Calcium and phosphorus metabolism in renal failure. PTH, parathyroid hormone; FGF-23, fibroblasts growth factor 23 .

parathyroid glands leads to vitamin $\mathrm{D}$ resistance. The loss of negative feedback on the parathyroid glands causes a high PTH level.

PTH secretion is appropriate in this case and, along with FGF-23, can decrease the tubular reabsorption of phosphorus to $<15 \%$. This is a relatively steady state: the phosphorus and calcium levels are back to normal but at the expense of high PTH and FGF-23. When GFR falls below $30 \mathrm{~mL} / \mathrm{min}$ (CKD stage IV), the tubular reabsorption of phosphorus cannot be further lowered, causing more PTH and FGF-23 secretion. Even though tubular reabsorption of phosphorus is maximally suppressed, there are too few nephrons left to balance the continuing phosphorus intake. Although PTH is no more active on the kidney, its action on the bone is maintained and continues to promote calcium and phosphorus release. The end result is a vicious cycle in which high phosphorus causes PTH secretion and PTH causes more hyperphosphatemia.

\section{Outcomes}

Secondary hyperparathyroidism is a very early disease and its diagnosis and treatment is crucial in the management of patients with CKD. Levin et $\mathrm{al}^{10}$ demonstrated that the PTH starts to increase as early as the beginning of CKD stage III (estimated GFR, $<60 \mathrm{~mL} / \mathrm{min}$ ), along with normal levels of serum calcium and phosphorus.

The effect of secondary hyperparathyroidism on mortality was thought to be mainly caused by hyperphosphatemia. The last phase of the Dialysis Outcomes and Practice Patterns Study identified hyperphosphatemia $\left(\mathrm{PO}_{4}>6.1 \mathrm{mg} / \mathrm{dL}\right)$, hypercalcemia $(\mathrm{Ca}>10 \mathrm{mg} / \mathrm{dL})$, and high PTH $(>600$ $\mathrm{pg} / \mathrm{mL}$ ) as 3 independent risk factors for all-cause and cardiovascular mortality, with hazard ratios of $1.18,1.16$, and 1.21 , respectively. ${ }^{11}$ Moreover, it is known that a calcium-phosphorus product $>72$ $\mathrm{mg}^{2} / \mathrm{dL}^{2}$ is associated with a $34 \%$ increased risk of mortality and metastatic calcification. This risk further increases by $11 \%$ for every 10 points of elevation of the calcium-phosphorus product. ${ }^{12}$

In addition, secondary hyperparathyroidism is the leading cause of renal osteodystrophy and bone disease. Renal osteodystrophy is sometimes called "the silent crippler"; affected patients may be completely asymptomatic. Symptoms, including bone and joint pain and bone deformation and fractures, are more frequent during the late stages of the disease. Osteitis fibrosa cystica, the classic and former most common osteodystrophy, is mainly caused by high bone turnover secondary to high levels of circulating PTH. The excessive suppression of PTH can lead to adynamic bone disease (currently the most common osteodystrophy), mainly because of low bone turnover. ${ }^{13}$ In fact, during the late stages of $\mathrm{CKD}$, the number of PTH receptors in the skeleton is downregulated, leading to what is known as skeletal resistance, a natural mechanism for the bone to defend itself against the high levels of PTH. This is why the current Kidney Disease Outcomes Quality Initiative (K/DOQI) recommendation is to keep PTH between 150 and $300 \mathrm{pg} / \mathrm{mL}$ to avoid a complete suppression of the osteoclasts and prevent adynamic bone disease. Another less common bone disorder caused by low bone turnover and vitamin D deficiency is osteomalacia, which is primarily characterized by an increased volume of unmineralized bone. Mixed osteodystrophy is also described as having elements of both high and low bone turnovers. Even though many patients have a predominant form of bone disease, most patients have several types and therefore fall into the mixed category.

\section{Management}

The management of secondary hyperparathyroidism should be started at the beginning of CKD stage III (estimated GFR, $<60 \mathrm{~mL} / \mathrm{min}$ ). It is a complex process that requires good communication between the nephrologist, the dietitian, and the patient. It is important to recognize the treatment 
Table 2. Frequency of Measurement and Target Ranges of Parathyroid Hormone (PTH) and Phosphorus According to Stage of Chronic Kidney Disease

\begin{tabular}{|c|c|c|c|c|c|}
\hline Stage & $\begin{array}{c}\text { GFR Range } \\
\left(\mathrm{mL} / \mathrm{min} / 1.73 \mathrm{~m}^{2}\right)\end{array}$ & $\begin{array}{c}\text { Measurement of } \\
\text { PTH }\end{array}$ & $\begin{array}{l}\text { Measurement of } \\
\text { Calcium and } \\
\text { Phosphorus }\end{array}$ & $\begin{array}{l}\text { Target } \mathrm{PO}_{4} \\
(\mathrm{mg} / \mathrm{dL})\end{array}$ & $\begin{array}{l}\text { Target PTH } \\
(\mathrm{pg} / \mathrm{mL})\end{array}$ \\
\hline III & 30 to 59 & Every 12 months & Every 12 months & 2.7 to 4.6 & 30 to 70 (level B) \\
\hline IV & 15 to 29 & Every 3 months & Every 3 months & 2.7 to 4.6 & 70 to 110 (level B) \\
\hline V & $<15$ or dialysis & Every 3 months & Every month & 3.5 to 5.5 & 150 to 300 (level A) \\
\hline
\end{tabular}

Adapted from the National Kidney Foundation 2003, used with permission.

GFR, glomerular filtration rate.

goals, which vary according to the stages of CKD. Serum levels of calcium, phosphorus, and intact PTH should be measured in all patients with CKD and estimated GFR $<60 \mathrm{~mL} / \mathrm{min}$. The National Kidney Foundation K/DOQI guidelines provide frequency of measurements and goals for serum phosphorus and PTH according to CKD stage, listed below ${ }^{14}$ (Table 2). The treatment of secondary hyperparathyroidism basically consists of a low phosphorus diet, phosphate binders, vitamin D derivatives, calcimimetics, and even parathyroidectomy.

\section{Stepped Approach}

The management of secondary hyperparathyroidism can be divided in 3 main steps (Table 3):

1. The goal of the first step is to optimize the levels of serum phosphorus and calcium (within the recommended ranges, depending on stage of $\mathrm{CKD})$. This can be achieved by dietary restriction and the initiation of phosphate binders (calcium acetate, sevelamer, or lanthanum). In CKD stages III and IV, ergocalciferol should be considered if the 25-hydroxyvitamin D level is $<30 \mathrm{ng} / \mathrm{mL}$.
2. Step 2 should focus on the control of PTH and vitamin $\mathrm{D}$ levels by the use of calcimimetics and/or vitamin $\mathrm{D}$ analogues. If calcium and phosphorus levels are close to the upper limit of normal, then cinacalcet should be considered. On the other hand, at calcium levels closer to the lower limit of normal, vitamin D analogues would be a better choice.

3. In step 3, the doses of phosphate binders, calcimimetics, and vitamin $\mathrm{D}$ analogues should be adjusted to achieve the K/DOQI values.

\section{Low-Phosphorus Diet}

For patients with CKD stages III and IV (level B), a low-phosphorus diet should be initiated when serum phosphorus is above $4.6 \mathrm{mg} / \mathrm{dL}$ and when serum phosphorous is above $5.5 \mathrm{mg} / \mathrm{dL}$ in patients with CKD stage $\mathrm{V}$ (level A), or when the measured intact PTH is above the target range of the CKD stage, even with normal levels of phosphorus and calcium (level A). Unfortunately, this is very difficult to achieve because phosphorus is omnipresent in our diet. In fact, the dietary phosphorus is mainly derived from 2 sources: dietary proteins and phosphorus additives. These additives are an important component of processed foods such as meats,

Table 3. Stepped Approach for Management of Secondary Hyperparathyroidism

\begin{tabular}{|c|c|c|}
\hline Step & Drugs Used & Goals \\
\hline I & $\begin{array}{l}\cdot \text { Low-phosphorus diet } \\
\cdot \text { Phosphate binders } \\
\cdot \text { Ergocalciferol (stages III and IV) }\end{array}$ & $\begin{array}{l}\text { - Calcium and phosphorus within normal ranges } \\
\text { (depending on stage of CKD) } \\
\cdot 25 \text {-hydroxyvitamin } D>30 \mathrm{pg} / \mathrm{mL}\end{array}$ \\
\hline II & $\begin{array}{l}\text { - Cinacalcet } \\
\text { - Vitamin D sterols (calcitriol, paricalcitol, } \\
\text { and doxecalciferol) }\end{array}$ & $\begin{array}{l}\text { - PTH within normal ranges (depending on } \\
\text { stage of CKD) }\end{array}$ \\
\hline III & - Adjust doses & $\begin{array}{l}\text { - Calcium, phosphorus, and } \mathrm{PTH} \text { within } \mathrm{K} / \mathrm{DOQI} \\
\text { recommendations }\end{array}$ \\
\hline
\end{tabular}

CKD, chronic kidney disease; PTH, parathyroid hormone; K/DOQI, Kidney Disease Outcomes Quality Initiative. 
Table 4. Phosphorus Content of Common Foods that Contain Protein

\begin{tabular}{|c|c|c|c|c|c|c|c|c|}
\hline Food & $\begin{array}{c}\text { Soybeans } \\
\text { (roasted) }\end{array}$ & $\begin{array}{l}\text { Cream } \\
\text { Cheese }\end{array}$ & $\begin{array}{l}\text { Roast Beef } \\
\text { Sandwich }\end{array}$ & Pork & $\begin{array}{l}\text { Chicken } \\
\text { Breast }\end{array}$ & Shrimp & $\begin{array}{l}\text { Peanut } \\
\text { Butter }\end{array}$ & Lemonade \\
\hline Measurement & 1 cup & $2 \mathrm{tb}$ & 1 sandwich & $3 \mathrm{oz}$ & $3 \mathrm{oz}$ & $3 \mathrm{oz}$ & $2 \mathrm{tb}$ & 1 cup \\
\hline Protein (g) & 61 & 2 & 21.5 & 22 & 27 & 18 & 8 & 0.3 \\
\hline Phosphorus (mg) & 624 & 30 & 239 & 146 & 196 & 116 & 101 & 5 \\
\hline $\begin{array}{l}\mathrm{Mg} \text { (phosphorus) } / \mathrm{g} \\
\text { (protein) }\end{array}$ & 10.2 & 15 & 11.1 & 6.6 & 7.3 & 6.4 & 12.6 & 16.7 \\
\hline
\end{tabular}

Adapted from the National Kidney Foundation 2003, used with permission.

$\mathrm{Tb}$, tablespoon; oz, ounce.

cheeses, dressings, beverages, and bakery products. They can increase the dietary phosphorus intake by as much as $1 \mathrm{~g} /$ day. ${ }^{15}$ Nutrient composition tables usually do not include the phosphorus additives, which results in underestimation of phosphorus intake. Moreover, the phosphorus derived from plants is in the form of phytate and is less absorbable by the human intestines because of a lack of the enzyme phytase. Table 4 illustrates the phosphorus content of some common foods that contain protein.

In a study of 29,076 patients on hemodialysis, Shinaberger et $\mathrm{al}^{16}$ demonstrated that a high-protein/low-phosphorus diet is associated with the best survival, and the highest mortality rate was found in patients on low-protein/low-phosphorus diet. This study reflects the effect of dietary proteins on the survival of patients on hemodialysis. The current $\mathrm{K} / \mathrm{DOQI}$ guidelines for patients with CKD are to restrict dietary phosphorus to 800 to $1000 \mathrm{mg} /$ day, adjusted for dietary protein needs. ${ }^{14}$

\section{Phosphate Binders}

Phosphate binders are the mainstay of therapy for secondary hyperparathyroidism. The noncompliance to dietary restriction as well as the need to ensure adequate protein intake often result in the addition of phosphate binders to limit the net absorption of dietary phosphorus. In a recent study published in December 2008, patients treated with phosphate binders during the first 90 days after starting dialysis had a $30 \%$ lower risk of death compared with those who were not treated. ${ }^{17} \mathrm{Sev}-$ eral modalities have been tried, including aluminum hydroxide, calcium salts, sevelamer hydrochloride (Renagel, Genzyme Corp., Cambridge, MA) and lanthanum carbonate (Fosrenol, Shire US, Inc., Wayne, PA).

\section{Aluminum Hydroxide}

It is the former phosphate binder of choice and the oldest treatment for hyperphosphatemia. It forms nonabsorbable aluminum-phosphorus precipitates in the intestines and is very effective in lowering phosphatemia levels. It is still the most potent phosphate binder. Aluminum hydroxide should be prescribed by nephrologists and its use should be limited to a short period of time because of the risk of aluminum toxicity. In fact, the accumulation of aluminum in the body leads to severe refractory microcytic anemia, dementia, osteomalacia, and other problems. There is no known safe dose to avoid aluminum intoxication. In patients with serum phosphorus levels of $>7.0 \mathrm{mg} / \mathrm{dL}$, the current $\mathrm{K} / \mathrm{DOQI}$ guidelines advise the use of aluminum hydroxide for $<4$ weeks and for one course only. ${ }^{14}$

\section{Calcium Salts}

The 2 most commonly used calcium salts in the United States are calcium carbonate (eg, Tums, GlaxoSmithKline, Research Triangle Park, NC) and calcium acetate (eg, PhosLo, Nabi Biopharmaceuticals, Rockville, MD). They bind to dietary phosphorus and form a nonabsorbable precipitate in the intestines. Calcium acetate is twice as potent as calcium carbonate and induces less hypercalcemia. ${ }^{18}$ Calcium acetate contains only $169 \mathrm{mg}$ of elemental calcium versus 200 to $600 \mathrm{mg}$ in calcium carbonate. This is important to know when dealing with hypercalcemia induced by calcium salts, a major complication that limits the use of calcium salts. The K/DOQI guidelines currently recommend a total dose of elemental calcium $<1.5 \mathrm{~g} /$ day $^{14}$ (equivalent to 9 tablets of PhosLo [Nabi Biopharmaceuticals]). Calcium salts are contraindicated in patients with serum calcium levels of $>10.5 \mathrm{mg} / \mathrm{dL}$ and in patients with persistently elevated phosphorus and adynamic bone disease. 


\section{Sevelamer Hydrochloride}

Sevelamer hydrochloride (Renagel, Genzyme Corp.) was approved by the Food and Drug Administration in 2000 for the treatment of hyperphosphatemia in patients with CKD. It is noncalcium, nonaluminum, and nonmagnesium based. It forms a cationic polymer that binds to dietary phosphorus through ion exchange. Studies have proved the efficacy of sevelamer and currently it is widely used in the United States. Sevelamer is 10 times more expensive than calcium-based phosphate binders. Several studies have evaluated its relative efficacy compared with calcium-based products.

In the treat-to-goal trial, patients using sevelamer had less incidence of hypercalcemia, lower low-density lipoprotein levels, and lesser degrees of calcification in the coronary arteries. ${ }^{19}$ The Dialysis Clinical Outcomes Revisited Trial is one of the most important trials that compared calcium acetate and sevelamer. It included 2107 patients followed for 45 months and showed no difference in mortality between the 2 groups. ${ }^{20}$ Further prespecified analysis showed a decrease in all-causebut not cardiovascular-mortality among patients $>65$ years of age who were assigned to sevelamer. This study was followed by a meta-analysis that reported no difference in all-cause mortality between the 2 groups. $^{21}$

\section{Sevelamer Carbonate}

A side effect of sevelamer is the induction of metabolic acidosis. This has led to the replacement of chloride ion with a carbonate. The new product is sevelamer carbonate, or Renvela (Genzyme Corp.). It was approved in December 2007. Sevelamer carbonate has the same efficacy as sevelamer hydrochloride but with less metabolic acidosis and therefore less adverse gastrointestinal effects. ${ }^{22}$

\section{Lanthanum Carbonate (Fosrenol, Shire US, Inc.)}

Lanthanum is a rare earth element and has the property of phosphorus binding. It was approved by the Food and Drug Administration in 2004. It is effective in lowering serum phosphorus level, but is also very expensive. Moreover, its long-term safety needs to be determined, particularly regarding its possible accumulation in the liver, kidney, or other organs. In a study of 1359 hemodialysis patients assigned to lanthanum or prestudy standard therapy and followed for 2 years, Finn ${ }^{23}$ found similar efficacy in controlling hyperphosphatemia but with fewer incidences of hypercalcemia and better PTH control in patients receiving lanthanum. A similar study was done among patients with CKD stages III and IV, comparing lanthanum versus placebo. That study also showed better outcomes in the lanthanum-treated group. ${ }^{24}$

\section{Conclusions}

To help clarify the use of this wide variety of phosphate binders, the K/DOQI guidelines are as follows ${ }^{14}$ :

1. All phosphate-binding agents are effective in lowering serum phosphorus levels (level A) and may be used as the primary therapy (except those that are aluminum or magnesium based [level B]).

2. If needed, a combination of 2 can be used (level B).

3. Calcium-based binders should be avoided when $\mathrm{Ca}$ is $>10.5 \mathrm{mg} / \mathrm{dL}$ (level A).

4. Elemental calcium provided by the calciumbased phosphate binders should not exceed 1500 mg/day (level B).

\section{Vitamin D and Its Derivatives}

Vitamin D is one of the oldest treatments for secondary hyperparathyroidism. It is known that calcitriol deficiency and resistance are major contributors to the pathophysiology of the disease and that calcitriol supplementation is effective in suppressing high levels of PTH. On the other hand, calcitriol enhances the intestinal absorption of calcium and phosphorus, increasing their blood levels and possibly increasing their product. Several observational studies have shown improved survival in patients treated with intravenous vitamin $\mathrm{D}$, but randomized controlled studies to confirm survival benefits are still lacking. In fact, a meta-analysis done in 2007 showed no difference in mortality, bone pain, vascular calcifications, or rate of parathyroidectomies between patients treated with vitamin D compounds and those who received placebo. ${ }^{25}$ Calcitriol $(1,25$ dihydroxyvitamin D3) is the natural form of vitamin $\mathrm{D}$ produced by the human body. Studies have shown that intermittent, intravenous administration of calcitriol is more effective than daily oral calcitriol in lowering serum PTH levels. ${ }^{26}$ Several forms of vitamin D and its derivatives are available on the market: 


\section{Ergocalciferol}

Ergocalciferol (eg, $\delta$ lin) (Eli Lilly and Company, Indianapolis, $\mathrm{IN}$ ) is vitamin $\mathrm{D}_{2}$ or the nutritional vitamin $\mathrm{D}$. To be active, it needs to be metabolized in the liver and the kidneys, which would require at least some activity of the 1- $\alpha$ hydroxylase. Recently, it has been recognized that low levels of 25-hydroxyvitamin D-and not only of the vitamin $\mathrm{D}$ active form (1,25 dihydroxyvitamin D)—can contribute to the development of secondary hyperparathyroidism. ${ }^{27}$ Ergocalciferol is only indicated in patients with CKD stages III and IV if the 25 -hydroxyvitamin D level is $<30 \mathrm{ng} / \mathrm{mL}$. There is currently inadequate evidence to support the benefits of ergocalciferol use in dialysis patients (CKD stage $\mathrm{V}$ ).

\section{Selective Vitamin D Analogues}

The problem with the increased intestinal absorption of calcium and phosphorus after administration of cacitriol led to the development of selective agents that have more affinity to the kidney rather than intestinal receptors. These second-generation agents cause less hypercalcemia and hyperphosphatemia than traditional calcitriol. Two agents are available and widely used in the United States: paricalcitol (eg, Zemplar, Abbott Laboratories, Abbott Park, IL) and doxercalciferol (Hectorol, Genzyme Corp.). In a large study including 69,492 patients undergoing dialysis in Fresenius facilities, patients treated with paricalcitol had a $16 \%$ lower mortality rate than those who received calcitriol, in addition to lower levels of calcemia and phosphatemia and a better PTH control. ${ }^{28}$

\section{Conclusions}

The K/DOQI guidelines regarding vitamin D use in patients with CKD are as follows ${ }^{14}$ :

1. Ergocalciferol should be used in CKD stages III and IV when serum level of 25-hydroxyvitamin $\mathrm{D}$ is $<30 \mathrm{ng} / \mathrm{mL}$ (level B).

2. Active oral vitamin D sterols (calcitriol, paricalcitol, or doxercalciferol) are indicated when serum level of 25 -hydroxyvitamin $\mathrm{D}$ is $>30$ $\mathrm{ng} / \mathrm{mL}$ with high PTH in CKD stages III and IV (level A).

3. Active vitamin $\mathrm{D}$ sterols are indicated when $\mathrm{Ca}$ is $<9.5 \mathrm{mg} / \mathrm{dL}, \mathrm{PO}_{4}$ is $<5.5 \mathrm{mg} / \mathrm{dL}$, and PTH is $>300 \mathrm{pg} / \mathrm{mL}$ in CKD stage $\mathrm{V}$ (level A).
4. Intermittent intravenous use is more effective than oral use in dialysis patients (level A).

\section{Calcimimetics}

Calcimimetics are new agents that allosterically increase the sensitivity to calcium of calcium-sensing receptors in the parathyroid glands, thus suppressing PTH secretion. Cinacalcet (Sensipar, Amgen Inc., Thousand Oaks, CA) is the only Food and Drug Administration-approved calcimimetic for use in dialysis patients. It was introduced to the market in 2004. In a study including 1136 hemodialysis patients with PTH $>300 \mathrm{pg} / \mathrm{mL}$, patients assigned to traditional therapy plus cinacalcet had better achievement of the K/DOQI guidelines $(\mathrm{PTH}<300$ and calcium $\mathrm{x}$ phosphate $<55)$ than those who were assigned to traditional therapy plus placebo ( $41 \%$ vs $6 \%) .{ }^{29}$ Cinacalcet may be used in combination with vitamin $\mathrm{D}$ and is contraindicated in patients with $\mathrm{Ca}$ levels $<8.4 \mathrm{mg} / \mathrm{dL}$. Its side effects include gastrointestinal symptoms and QT prolongation, mostly related to hypocalcemia. $\mathrm{Ci}-$ nacalcet is indicated only in dialysis patients with Ca levels $>8.4 \mathrm{mg} / \mathrm{dL}$ and PTH levels $>300 \mathrm{pg} /$ $\mathrm{mL}$. Unfortunately, there is lack of studies addressing the use of cinacalcet in patients with CKD stages III and IV.

\section{Parathyroidectomy}

This is only used when all medical therapy is unsuccessful. Its efficacy is well documented. ${ }^{30}$ In addition, the presence of extraskeletal calcification, calciphylaxis, debilitating bone disease, refractory pruritus, severe hypercalcemia, and PTH levels $>800 \mathrm{pg} / \mathrm{mL}$ are strong indications for surgical treatment. It can be performed by either subtotal or total parathyroidectomy with autotransplantation. Small amounts of resected parathyroid tissue can be autografted in the muscles of the forearm or neck, as well as in the subcutaneous tissue of the chest or abdomen. The lack of osteoclastic activity caused by a decrease in PTH postoperatively may lead to a precipitous fall in calcium levels, a condition called"hungry-bone syndrome." This is why patient follow-up after the surgery is extremely important and should include monitoring of the total and ionized calcium levels.

\section{References}

1. Poggio ED, Rule AD. A critical evaluation of chronic kidney disease-should isolated reduced esti- 
mated glomerular filtration rate be considered a 'disease’? Nephrol Dial Transplant 2009;24:698-700.

2. Coresh J, Selvin E, Stevens L, et al. Prevalence of chronic kidney disease in the United States. JAMA 2007;298:2038-47.

3. Komaba H, Goto S, Fukagawa M. Critical issues of PTH assays in CKD. Bone. 2009;44:666-70.

4. Biber J, Custer M, Magagnin S, et al. Renal Na/Picotransporters. Kidney Int 1996;49:981.

5. Brown EM, Hebert SC. Calcium-receptor-regulated parathyroid and renal function. Bone 1997;20:303-9.

6. Slatopolsky E, Finch J, Denda M, et al. Phosphorus restriction prevents parathyroid gland growth. High phosphorus directly stimulates PTH secretion in vitro. J Clin Invest 1996;97:2534-40.

7. Holick MF. Vitamin D and the kidney. Kidney Int 1987;32:912-29.

8. Nabeshima Y. Clinical discovery of alpha-Klotho and FGF-23 unveiled new insight into calcium and phosphate homeostasis. Calcium 2008;18:923-34.

9. Kovesdy CP, Kalantar-Zadeh K. Bone and mineral disorders in pre-dialysis CKD. Int Urol Nephrol 2008;40:427-40.

10. Levin A, Bakris GL, Molitch M, et al. Prevalence of abnormal serum vitamin D. PTH, calcium, and phosphorus in patients with chronic kidney disease: results of the study to evaluate early kidney disease. Kidney Int 2007;71:31-8.

11. Tentori F, Blayney MJ, Albert JM, et al. Mortality risk for dialysis patients with different levels of serum calcium, phosphorus, and PTH: the Dialysis Outcomes and Practice Patterns Study (DOPPS). Am J Kidney Dis 2008;52:519-30.

12. Block GA, Hulbert-Shearon TE, Levin NW, Port FK. Association of serum phosphorus and calcium $X$ phosphate product with mortality risk in chronic hemodialysis patients: a national study. Am J Kidney Dis 1998;31:607-17.

13. Andress DL. Adynamic bone in patients with chronic kidney disease. Kidney Int 2008;73:1345-54.

14. National Kidney Foundation. K/DOQI clinical practice guidelines for bone metabolism and disease in chronic kidney disease. Am J Kidney Dis 2003; 42(4 Suppl 3):S1-201.

15. Uribarri J, Calvo MS. Hidden sources of phosphorus in the typical American diet: does it matter in nephrology? Semin Dial 2003;16:186-8.

16. Shinaberger CS, Kilpatrick RD, Regidor DL, et al. Longitudinal associations between dietary protein intake and survival in hemodialysis patients. Am J Kidney Dis 2006;48:37-49.

17. Isakova T, Gutiérrez OM, Chang Y, et al. Phosphorus binders and survival on hemodialysis. J Am Soc Nephrol 2009;20:388-96.
18. Delmez JA, Tindira CA, Windus DW, et al. Calcium acetate as a phosphorus binder in hemodialysis patients. J Am Soc Nephrol 1992;3:96-102.

19. Chertow GM, Burke SK, Raggi P, Treat to Goal Working Group. Sevelamer attenuates the progression of coronary and aortic calcification in hemodialysis patients. Kidney Int. 2002;62:245-52.

20. Suki WN, Zabaneh R, Cangiano JL, et al. Effects of sevelamer and calcium-based phosphate binders on mortality in hemodialysis patients. Kidney Int 2007; 72:1130-7.

21. Tonelli M, Wiebe N, Culleton B, et al. Systematic review of the clinical efficacy and safety of sevelamer in dialysis patients. Nephrol Dial Transplant 2007; 22:2856-66.

22. Delmez J, Block G, Robertson J, et al. A randomized, double-blind, crossover design study of sevelamer hydrochloride and sevelamer carbonate in patients on hemodialysis. Clin Nephrol 2007;68:386-91.

23. Finn WF, SPD 405-307 Lanthanum Study Group. Lanthanum carbonate versus standard therapy for the treatment of hyperphosphatemia: safety and efficacy in chronic maintenance hemodialysis patients. Clin Nephrol 2006;65:191-202.

24. Sprague SM, Abboud H, Qiu P, Dauphin M, Zhang $\mathrm{P}$, Finn $W$. Lanthanum carbonate reduces phosphorus burden in patients with CKD stages 3 and 4: a randomized trial. Clin J Am Soc Nephrol 2009;4: $178-85$.

25. Palmer SC, McGregor DO, Macaskill P, Craig JC, Elder GJ, Strippoli GF. Meta-analysis: vitamin D compounds in chronic kidney disease. Ann Intern Med 2007;147:840-53.

26. Bacchini G, Fabrizi F, Pontoriero G, Marcelli D, Di Filippo S, Locatelli F. 'Pulse oral' versus intravenous calcitriol therapy in chronic hemodialysis patients. A prospective and randomized study. Nephron 1997; 77:267-72.

27. Cuppari L, Garcia-Lopes MG. Hypovitaminosis d in chronic kidney disease patients: prevalence and treatment. J Ren Nutr 2009;19:38-43.

28. Teng M, Wolf M, Lowrie E, Ofsthun N, Lazarus JM, Thadhani R. Survival of patients undergoing hemodialysis with paricalcitol or calcitriol therapy. N Engl J Med 2003;349:446-56.

29. Moe SM, Chertow GM, Coburn JW, et al. Achieving NKF-K/DOQI bone metabolism and disease treatment goals with cinacalcet HCL. Kidney Int 2005;67:760-71.

30. Kostakis A, Vaiopoulos G, Kostantopoulos K, Zavos G, Bocos I, Sgouromalis S. Parathyroidectomy in the treatment of secondary hyperparathyroidism in chronic renal failure. Int Surg 1997;82:85-6. 